Research Paper

\title{
Survival analysis for lung adenosquamous carcinoma patients with brain metastasis
}

\author{
Feng Pan, Shaohua Cui, Weimin Wang, Aiqin $\mathrm{Gu}^{凶}$, Liyan Jiang ${ }^{\bowtie}$ \\ Department of Respiratory Medicine, Shanghai Chest Hospital, Shanghai Jiao Tong University, Shanghai, China \\ $\triangle$ Corresponding authors: Liyan Jiang, Department of Respiratory Medicine, Shanghai Chest Hospital, Shanghai Jiao Tong University, 241\# Huai Hai (W.) Rd, \\ Shanghai, China. Tel: +86 13916146759; Fax: +86 021-32260856; E-mail contact: Jiang_liyan2000@126.com and Aiqin Gu, Department of Respiratory Medicine, \\ Shanghai Chest Hospital, Shanghai Jiao Tong University, 241\# Huai Hai (W.) Rd, Shanghai, China. Tel: +86 13916720655; Fax: +86 021-32260856; E-mail contact: \\ guaiqin11@126.com \\ (C) Ivyspring International Publisher. This is an open access article distributed under the terms of the Creative Commons Attribution (CC BY-NC) license \\ (https://creativecommons.org/licenses/by-nc/4.0/). See http://ivyspring.com/terms for full terms and conditions.
}

Received: 2018.05.23; Accepted: 2018.07.09; Published: 2018.09.08

\begin{abstract}
Purpose: We retrospectively collected consecutive survival data of lung adenosquamous cell carcinoma (ASC) patients with brain metastasis (BM) in our institute and discussed the factors related to prognosis of these patients.

Patients and Methods: A total of 42 patients diagnosed as lung ASC with BM between July 1, 2008 and December 31, 2010 at the Department of Respiratory Medicine, Shanghai Chest Hospital, Shanghai Jiao Tong University were retrospectively reviewed. Time to BM (TTB) and overall survival (OS) data were analyzed. OS1 was calculated from the time ASC was diagnosed until the death of a patient. OS2 was defined as the duration from BM was first identified to the death of a patient. 1-year, 2-year and 3-year survival rates were also computed. Univariate and multivariate survival analysis was performed using Kaplan-Meier methods and Cox regression.

Results: The median TTB for all patients was 5.7 months [95\% confidence interval (Cl): $0.8-10.6$ months]. The median OSI was 13.8 months ( $95 \% \mathrm{Cl}$ : $11.2-16.4$ months). TTB longer than 12 months [adjusted HR: 0.15 ( $95 \% \mathrm{Cl}: 0.05-0.48$ vs. TTB 6 months, $P=0.001)$; 0.22 ( $95 \% \mathrm{Cl}: 0.07-0.71$, vs. TTB $6-12$ months, $P=0.010)$ and resection for $B M$ lesions [adjusted hazard ratio (HR): 0.47 ( $95 \% \mathrm{Cl}: 0.24-0.94$ vs. not resected, $P=0.032$ )] were independent predictors for a longer OS1. The median OS2 was 7.9 months $(95 \% \mathrm{Cl}$ : $4.5-11.3$ months). Treatment cycles more than 3 [adjusted HR: $0.41(95 \% \mathrm{Cl}: 0.20-0.83$ vs. treatment cycles $<3, P=0.013)$ ] was an independent predictor for a longer OS2.

Conclusions: This study shows that resection of BM if possible, and standard chemo-radiotherapy in patients with multiple BM lesions is associated with longer overall survival.
\end{abstract}

Key words: lung cancer; non-small-cell lung cancer (NSCLC); lung adenosquamous carcinoma (ASC); survival; brain metastasis (BM).

\section{Introduction}

Lung cancer remains the leading cause of cancer-related deaths worldwide, posing a great threat to human health [1]. Primary lung adenosquamous carcinoma (ASC) is a rare subtype of lung cancer, accounting for about $0.4 \%$ to $4 \%$ of all lung carcinomas [2-5]. Thus, the recognition of ASC is significant in clinical practice as previously it received far less attention in prognostic aspects. The 2015 World Health Organization (WHO) classification of lung tumors defined ASC as "a carcinoma showing components of both squamous cell carcinoma and adenocarcinoma, with each comprising to at least $10 \%$ of the tumor." [6]

Existed evidence have revealed that ASC is an extremely aggressive subtype of lung tumors as patients with primary lung ASC had a poorer prognosis compared with those with a pure adenocarcinoma or squamous cell carcinoma subtype $[2,7,8]$. In recent years, targeted therapies such as epidermal growth factor receptor tyrosine kinase inhibitors (EGFR-TKIs), are playing an increasingly important role in the treatment of advanced 
non-small-cell lung cancer (NSCLC) patients with sensitive mutations. However, EGFR sensitive mutations are mostly harbored in patients with a pure adenocarcinoma type. For advanced lung ASC, standard platinum-based doublet chemotherapy is the main treatment regimen, which has limited efficacy.

Brain metastasis (BM) is a major cause of mortality and morbidity in lung cancer. It has been reported that $\mathrm{BM}$ are found in approximately $50 \%$ of all lung cancer patients [9]. BM in ASC patients is statistically in greater numbers than in patients with pure adenocarcinoma and squamous patients [2]. To data, the prognosis for primary lung ASC with BM has not yet been analyzed. In this observational study, we retrospectively collected consecutive survival data of ASC patients in our institute and discussed the factors related to their prognosis.

\section{Patients and Methods}

\section{Patients}

A total of 42 patients diagnosed as lung ASC with BM between July 1, 2008 and December 31, 2010 at the Department of Respiratory Medicine, Shanghai Chest Hospital, Shanghai Jiao Tong University, were retrospectively reviewed in this study. These patients were histologically diagnosed as primary lung ASC firstly and occurred BM identified by enhanced magnetic resonance imaging (MRI) of the brain during our study time. All patients were followed to death. Patients who lost to follow-up and had missing survival data were excluded. The main end points of this study were time to BM (TTB), OS1 and OS2. TTB was defined as the time from the date ASC was diagnosed until the date of BM identified according to enhanced MRI examination. OS1 was calculated from the time ASC was diagnosed until the death of a patient. OS2 was defined as the duration from BM was first identified to the death of a patient. The cutoff date for the study was September 1, 2016.

Clinical factors including age, gender, tumor differentiations, clinical stages at the time when ASC was diagnosed, time of BM occurrence, BM numbers, $\mathrm{BM}$ locations, treatment information for $\mathrm{BM}$, and some biomarker levels including P53, NM23 and vascular endothelial growth factor (VEGF) were collected in the study. Resection for BM included BM resection using stereotactic radiotherapy and surgery methods.

This study was approved by the Ethics Committee of Shanghai Chest Hospital, Shanghai Jiao Tong University, Shanghai. As this is an observationally retrospective study, patient consent is not required by the Ethics Committee of Shanghai
Chest Hospital, Shanghai Jiao Tong University. All data related to patient were kept confidentiality.

\section{Statistical Analysis}

Survival data were all presented as "months". 1-year, 2-year and 3-year survival rates were also computed. All descriptive survival data were presented along with a 95\% confidence interval $(95 \% \mathrm{CI})$. A stacked bar chart was generated to show the relationships among survival data for all cases. Kaplan-Meier methods and log-rank tests were used to analysis OS data and select factors with $P$-values less than 0.05 in different levels, then a Cox proportional hazards model using Enter method was performed to further identify independent prognostic factors associated with OS. All confidence intervals reported were 2-sided, and $P$ values less than 0.05 were considered statistically significant. All statistical analyses and figure generation were performed using SPSS ${ }^{\circledR}$ software, version 13.0 (SPSS Inc., Chicago, IL, USA).

\section{Results}

\section{Demographic and clinical characteristics of the ASC patients}

The demographic and clinical characteristics of the 42 ASC patients are shown in Table 1. These patients tended to be young ( $<60$ years), male gender, and had low differentiated tumors. BM lesions were found to be more prevalent in cerebrum. Single BM lesion was more common than multiple metastases in these patients when they were first identified to occur BM. In addition, 29 patients were identified to occur $\mathrm{BM}$ during treatment, while 13 occurred $\mathrm{BM}$ at the time when ASC was diagnosed. The median TTB was 5.7 months (95\% CI: 0.8 - 10.6 months).

\section{General follow-up and survival data}

All patients died in this study. The relationships of survival data TTB, OS1 and OS2 for all patients are shown in Figure 1. The median OS1 was 13.8 months (95\%CI: 11.2 - 16.4 months, Figure 2A). When initial event was calculated from the time ASC was first diagnosed, the 1-year, 2-year and 3-year survival rates for ASC patients were $61.9 \%$ (26/42; 95\%CI: 47.2\% $76.6 \%), 26.2 \%(11 / 42 ; 95 \% \mathrm{CI}: 12.9 \%-39.5 \%)$ and $14.3 \%$ (6/42; 95\%CI: 3.7\% - 24.9\%), respectively.

The median OS2 was 7.9 months (95\%CI: 4.5 11.3 months, Figure 2B). When initial event was defined as BM was first identified, the 1-year, 2-year and 3-year survival rates for ASC patients were38.1\% (16/42; 95\%CI: $23.4 \%$ - 52.8\%), 9.5\% (4/42; 95\%CI: $0.6 \%-18.4 \%)$ and $4.8 \%(2 / 42 ; 95 \%$ CI: $0-11.3 \%)$, respectively. 


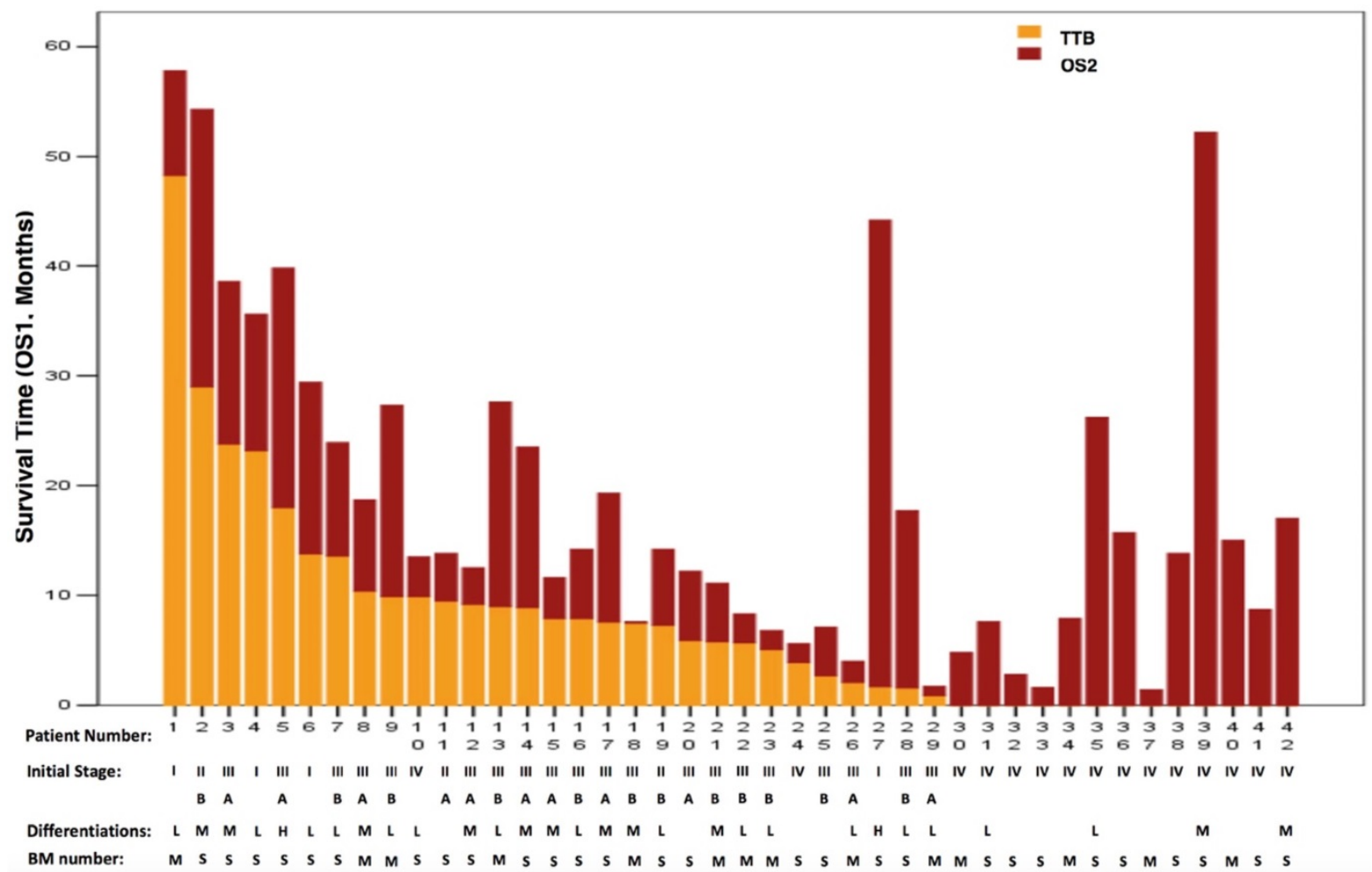

Figure 1: Survival data for all patients. BM: brain metastasis; TTB: time to brain metastasis; OS1: overall survival 1; OS2: overall survival 2; $B M$ number: $S=$ single; $M=$ multiple. Differentiations: $L=l o w ; M=$ moderate; $H=$ high.

Table 1. Demographic and clinical characteristics of the adenosquamous patients who occurred brain metastasis $(n=42)$

\begin{tabular}{|c|c|c|}
\hline \multicolumn{2}{|l|}{ Characteristics } & \multirow{2}{*}{$\begin{array}{l}\text { No. (\%) } \\
15(35.7)\end{array}$} \\
\hline Age, years & $\geq 60$ & \\
\hline & $<60$ & $27(64.3)$ \\
\hline & Mean (Range) & $\begin{array}{l}56(35- \\
76)\end{array}$ \\
\hline \multirow[t]{2}{*}{ Gender } & Male & $30(71.4)$ \\
\hline & Female & $12(28.6)$ \\
\hline \multirow[t]{4}{*}{ Differentiations } & Low & $16(38)$ \\
\hline & Moderate & $11(26.2)$ \\
\hline & High & $2(4.8)$ \\
\hline & Cannot be identified & $13(31)$ \\
\hline \multirow[t]{2}{*}{ Types } & Central & $22(52.4)$ \\
\hline & Peripheral & $20(47.6)$ \\
\hline \multirow{6}{*}{$\begin{array}{l}\text { Clinical stage (at the } \\
\text { time of diagnosis) }\end{array}$} & IA-B & $4(9.5)$ \\
\hline & IIA & $1(2.4)$ \\
\hline & IIB & $2(4.8)$ \\
\hline & IIIA & $10(23.8)$ \\
\hline & IIIB & $10(23.8)$ \\
\hline & IV & $15(35.7)$ \\
\hline \multirow[t]{2}{*}{ Time of BM } & Identified at the time of diagnosis & $13(31)$ \\
\hline & Identified after diagnosis & $29(69)$ \\
\hline \multirow[t]{2}{*}{ Locations } & Cerebrum & $37(88.1)$ \\
\hline & Other & $5(11.9)$ \\
\hline \multirow[t]{2}{*}{ Numbers of BM } & Single lesion & $28(66.7)$ \\
\hline & Multiple lesions & $14(33.3)$ \\
\hline \multirow{4}{*}{$\begin{array}{l}\text { Whether brain was } \\
\text { the first metastatic } \\
\text { site }\end{array}$} & Yes & $4(9.5)$ \\
\hline & No & $6(14.3)$ \\
\hline & Concurrent with other sites & $15(35.7)$ \\
\hline & Cannot be identified & $17(40.5)$ \\
\hline \multirow{6}{*}{$\begin{array}{l}\text { Therapies after brain } \\
\text { metastasis was } \\
\text { identified }\end{array}$} & Chemotherapy & $2(4.8)$ \\
\hline & Whole brain radiotherapy & $4(9.5)$ \\
\hline & Chemotherapy and whole brain radiotherapy & $21(50)$ \\
\hline & $\begin{array}{l}\text { Stereotaxic radiosurgery, chemotherapy and } \\
\text { whole brain radiotherapy }\end{array}$ & $2(4.8)$ \\
\hline & $\begin{array}{l}\text { Surgery, chemotherapy and whole brain } \\
\text { radiotherapy }\end{array}$ & $1(2.4)$ \\
\hline & Symptomatic treatment & $3(7.1)$ \\
\hline
\end{tabular}

\begin{tabular}{lll}
\hline Characteristics & & No. (\%) \\
\hline & Surgery and chemotherapy & $1(2.4)$ \\
& Stereotaxic radiosurgery and chemotherapy & $8(19)$ \\
Radiotherapy for & Yes & $15(35.7)$ \\
thoracic lesions & No & $27(64.3)$ \\
Surgery for thoracic & Yes & $29(69)$ \\
lesions & No & $13(31)$ \\
P53 & Positive & $11(26.2)$ \\
& Negative & $12(28.6)$ \\
& Cannot be identified & $19(45.2)$ \\
NM23 & Positive & $14(33.3)$ \\
& Negative & $8(19)$ \\
& Cannot be identified & $20(47.7)$ \\
VEGF & Positive & $6(14.3)$ \\
& Negative & $14(33.3)$ \\
& Cannot be identified & $22(52.4)$ \\
\hline
\end{tabular}

BM: Brain metastasis; VEGF: Vascular endothelial growth factor.

\section{Univariate and multivariate survival analysis for OS data}

The results of the univariate survival analysis by the Kaplan-Meier method and multivariate survival analysis by Cox regression for OS1 are shown in Table 2. The results suggested that TTB longer than 12 months (OS1: 38.6 months vs. 7.1 months for TTB less than 6 months; 38.6 months vs. 14.4 months for TTB 6-12 months; $P=0.001$ ), resection for BM lesions (OS1: 19.3 months vs. 11.6 months for those who did not resect $\mathrm{BM}$ lesions; $P=0.028$ ), receiving standard chemotherapy (OS1: 15.7 months vs. 7.6 months for those did not receive chemotherapy; $P=0.001$ ), and resection for thoracic lesions (OS1: 18.7 months vs. 7.9 months for those who did not have thoracic surgery; $P$ 
$<0.001)$ were all predictors of a longer OS1. However, results of multivariate analysis showed that only TTB and $\mathrm{BM}$ resection were independent predictors for a longer OS1 ( $P$-values were 0.002 and 0.020, respectively). For TTB $>12$ months, the adjusted hazard ratios (HR) for OS1 were 0.15 (95\%CI: 0.05 0.48 vs. TTB $\leq 6$ months, $P=0.001)$ and $0.22(95 \% \mathrm{CI}$ : $0.07-0.71$, vs. TTB 6-12 months, $P=0.010$; Figure $3 \mathrm{~A}$ ). For BM resection, the adjusted HR for OS1 was 0.47 (95\%CI: $0.24-0.94$ vs. not resected, $P=0.032$; Figure 3B).

The results of the univariate and multivariate survival analysis for OS2 are shown in Table 3. The analyses revealed that resection for BM lesions (OS2: 17.0 months vs. 4.8 months for those who did not

A

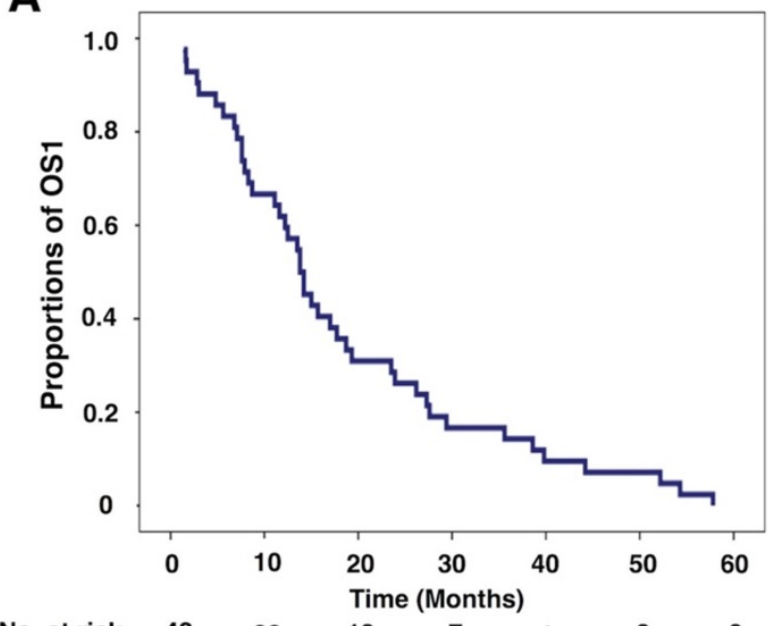

No. at risk: 42

7

4

3

0 No. at risk: 42

B

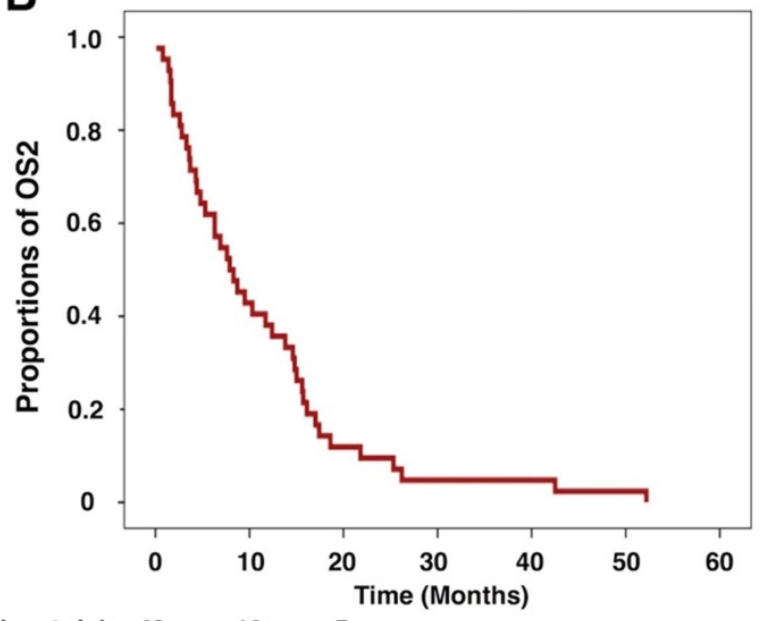

Figure 2: Kaplan-Meier curves for overall survival of primary lung adenosquamous carcinoma patients with brain metastasis. (A) The Kaplan-Meier curvefor OS1 of primary lung adenosquamous carcinoma patients with brain metastasis. The median OS1 was 13.8 months (95\%Cl: 11.2 - 16.4 months). (B) The Kaplan-Meier curve for OS2of primary lung adenosquamous carcinoma patients with brain metastasis. The median OS2 was 7.9 months ( $95 \% \mathrm{Cl}$ : 4.5 - 11.3 months). OS1: overall survival 1; OS2: overall survival 2.

Table 2. Survival analysis for OSI

\begin{tabular}{|c|c|c|c|c|c|}
\hline \multirow[t]{2}{*}{ Covariates } & \multirow[t]{2}{*}{ Comparisons } & \multicolumn{2}{|l|}{ Univariate survival analysis } & \multicolumn{2}{|c|}{ Multivariate survival analysis } \\
\hline & & Median OS1 in Months (95 \% CI) & $P$-value & $P$-value & Hazard Ratio (95\% CI) \\
\hline Age & $\geq 60$ years vs. $<60$ & $8.3(0.9-15.7)$ vs. $14.2(12.2-16.2)$ & 0.243 & & \\
\hline Gender & Male vs. Female & $13.8(11.8-15.8)$ vs. $12.2(6.9-17.5)$ & 0.206 & & \\
\hline Differentiations & Low vs. Moderate and High & $14.2(8.7-19.7)$ vs. $19.3(11.7-26.9)$ & 0.406 & & \\
\hline Time of BM & Initial vs. After first diagnosis & $8.7(1.4-16.0)$ vs. $14.2(7.3-21.1)$ & 0.113 & & \\
\hline $\begin{array}{l}\text { Duration of the time identified } \\
\text { cancer to occur BM }\end{array}$ & $\begin{array}{l}\leq 6 \text { months vs. } 6-12 \text { months vs. }>12 \\
\text { months }\end{array}$ & $\begin{array}{l}7.1(4.8-9.4) \text { vs. } 14.2(13.5-14.9) \\
\text { vs. } 38.6(30.9-46.3)\end{array}$ & $0.001^{*}$ & $0.002^{*}$ & $\begin{array}{l}10.447(2.752-39.658) \text { for } \\
6-12 \text { months } \\
6.831(1.876-24.873) \text { for }> \\
12 \text { months }\end{array}$ \\
\hline Locations & Cerebrum vs. Other & $14.2(12.4-16.0)$ vs. $7.6(3.3-11.9)$ & 0.258 & & \\
\hline Numbers of BM & Single vs. Multiple & $14.2(10.1-18.3)$ vs. $7.9(6.6-9.2)$ & 0.329 & & \\
\hline $\begin{array}{l}\text { Whether brain was the first } \\
\text { metastatic site }\end{array}$ & $\begin{array}{l}\text { Yes vs. No. vs. Concurrent with other } \\
\text { sites }\end{array}$ & $\begin{array}{l}19.3(1.1-37.5) \text { vs. } 13.5(11.9-15.1) \\
\text { vs. } 7.9(5.5-10.3)\end{array}$ & 0.054 & & \\
\hline Resection for BM lesion & Yes vs. No & $19.3(6.6-32.0)$ vs. $11.6(6.5-16.7)$ & $0.028^{*}$ & $0.020^{*}$ & $0.265(0.087-0.810)$ \\
\hline Standard chemotherapy & Yes vs. No & $15.7(11.9-19.5)$ vs. $7.6(2.5-12.7)$ & $0.001^{*}$ & 0.108 & $0.372(0.112-1.242)$ \\
\hline Radiotherapy for thoracic lesions & Yes vs. No & $15.0(12.9-17.1)$ vs. $11.6(4.6-18.6)$ & 0.656 & & \\
\hline Surgery for thoracic lesions & Yes vs. No & $18.7(14.7-22.7)$ vs. $7.9(4.3-11.5)$ & $<0.001^{*}$ & 0.560 & $0.673(0.177-2.553)$ \\
\hline Treatment cycles for BM & $<3$ cycles vs. $>3$ cycles & $7.9(6.5-9.3)$ vs. $23.5(12.8-34.2)$ & $0.010^{*}$ & & \\
\hline P53 & Positive vs. Negative & $18.7(6.8-30.6)$ vs. $13.5(8.2-18.8)$ & 0.895 & & \\
\hline NM23 & Positive vs. Negative & $17.7(0.6-34.8)$ vs. $11.1(0-25.5)$ & 0.889 & & \\
\hline VEGF & Positive vs. Negative & $19.3(7.4-31.2)$ vs. $12.5(7.7-17.3)$ & 0.792 & & \\
\hline
\end{tabular}

BM: Brain metastasis; OS: Overall survival; VEGF: Vascular endothelial growth factor.

$* P<0.05$. 
A

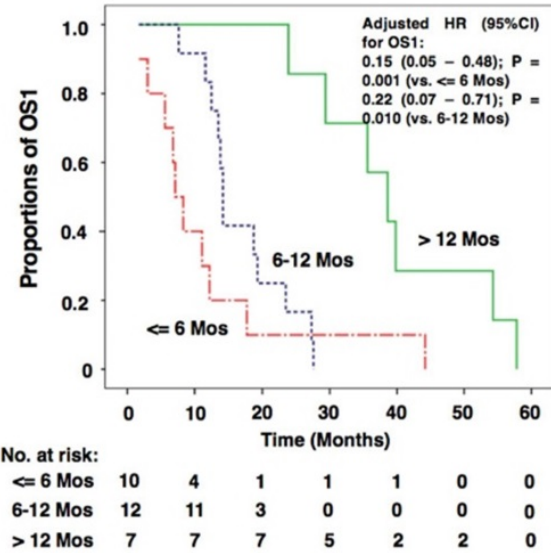

B

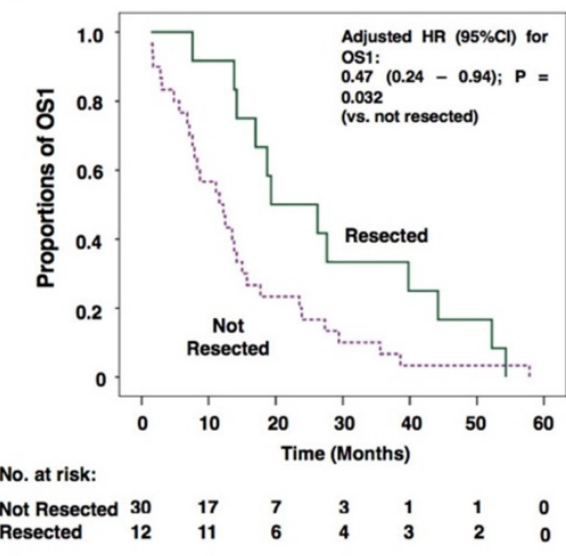

C

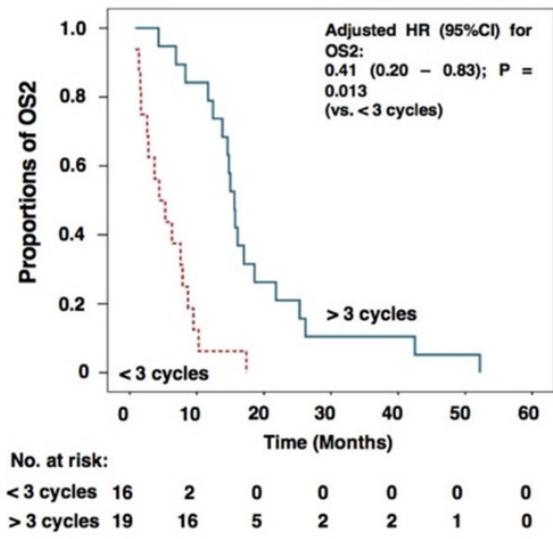

Figure 3: Kaplan-Meier curves of factors that independently influence OS1 and OS2. (A) Kaplan-Meier curves for OS1 of patients with TTB longer than 12 months, TTB 6-12 months and TTB $\leq 6$ months. TTB longer than 12 months were independent predictors for a longer OSI [adjusted HR: 0.15 (95\%Cl: $0.05-0.48$ vs. TTB $\leq$ months, $P=0.001) ; 0.22(95 \% \mathrm{Cl}: 0.07-0.71$, vs. TTB 6-12 months, $P=0.010$ ). (B) Kaplan-Meier curves for OSI of patients with BM lesions resected and not resected. Resection for BM lesions was an independent predictor for a longer OS2 [adjusted HR: 0.47 ( $95 \% \mathrm{Cl}: 0.24-0.94$ vs. not resected, $P=0.032)$ ]. (C) Kaplan-Meier curves for OS2 of patients with chemotherapy cycles more than 3 and patients with chemotherapy cycle less than 3 . Treatment cycles more than 3 was an independent predictor for a longer OS2 [adjusted HR: $0.41(95 \% \mathrm{Cl}: 0.20-0.83$ vs. treatment cycles $<3, P=0.013)$ ].

Table 3. Survival analysis for OS2

\begin{tabular}{|c|c|c|c|c|c|}
\hline \multirow[t]{2}{*}{ Covariates } & \multirow[t]{2}{*}{ Comparisons } & \multicolumn{2}{|l|}{ Univariate survival analysis } & \multicolumn{2}{|c|}{ Multivariate survival analysis } \\
\hline & & Median OS2 in Months $(95 \% \mathrm{CI})$ & $P$-value & $P$-value & Hazard Ratio (95\% CI) \\
\hline Age & $\geq 60$ years vs. $<60$ & $4.8(0-11.5)$ vs. $9.5(4.9-14.1)$ & 0.493 & & \\
\hline Gender & Male vs. Female & $8.7(5.1-12.3)$ vs. $6.3(4.6-8.0)$ & 0.130 & & \\
\hline Differentiations & Low vs. Moderate and High & $7.6(2.5-12.7)$ vs. $14.6(7.0-22.2)$ & 0.160 & & \\
\hline Time of BM & Initial vs. After first diagnosis & $8.7(1.4-16.0)$ vs. $6.9(2.9-10.9)$ & 0.376 & & \\
\hline $\begin{array}{l}\text { Duration of the time identified } \\
\text { cancer to occur BM }\end{array}$ & $\begin{array}{l}\leq 6 \text { months vs. } 6-12 \text { months vs. }>12 \\
\text { months }\end{array}$ & $\begin{array}{l}2.6(0-6.5) \text { vs. } 6.3(1.9-10.7) \text { vs. } \\
14.8(8.6-21.0)\end{array}$ & 0.249 & & \\
\hline Locations & Cerebrum vs. Other & $8.3(5.2-11.4)$ vs. $1.7(1.1-2.3)$ & 0.550 & & \\
\hline Numbers of BM & Single vs. Multiple & $10.3(4.1-16.5)$ vs. $4.8(0-9.8)$ & 0.056 & & \\
\hline $\begin{array}{l}\text { Whether brain was the first } \\
\text { metastatic site }\end{array}$ & $\begin{array}{l}\text { Yes vs. No. vs. Concurrent with other } \\
\text { sites }\end{array}$ & $\begin{array}{l}11.7(0-29.9) \text { vs. } 3.6(2.4-4.8) \text { vs. } \\
6.3(3.9-8.7)\end{array}$ & 0.063 & & \\
\hline Resection for BM lesion & Yes vs. No & $17.0(8.9-25.1)$ vs. $4.8(2.7-6.9)$ & $<0.001^{*}$ & 0.210 & $0.491(0.162-1.491)$ \\
\hline Chemotherapy & Yes vs. No & $10.3(5.5-15.1)$ vs. $3.3(0-6.9)$ & $<0.001^{*}$ & $\mathrm{df}=0$ & $\mathrm{df}=0$ \\
\hline Radiotherapy for thoracic lesions & Yes vs. No & $9.5(4.5-14.5)$ vs. $7.6(4.9-10.3)$ & 0.351 & & \\
\hline Surgery for thoracic lesions & Yes vs. No & $10.3(4.3-16.3)$ vs. $4.8(2.5-7.1)$ & $0.025^{*}$ & 0.113 & $0.505(0.217-1.176)$ \\
\hline Treatment cycles for BM & $<3$ cycles vs. $>3$ cycles & $4.4(1.3-7.5)$ vs. $15.6(14.3-16.9)$ & $<0.001^{*}$ & $0.006^{*}$ & $3.778(1.476-9.667)$ \\
\hline P53 & Positive vs. Negative & $14.6(1.2-28.0)$ vs. $6.3(2.4-10.2)$ & 0.116 & & \\
\hline NM23 & Positive vs. Negative & $14.6(0-30.2)$ vs. $7.6(3.4-17.8)$ & 0.199 & & \\
\hline VEGF & Positive vs. Negative & $12.4(8.7-16.1)$ vs. $5.3(0.5-10.1)$ & 0.769 & & \\
\hline
\end{tabular}

BM: Brain metastasis; OS: Overall survival; VEGF: Vascular endothelial growth factor.

${ }^{*} P<0.05$.

HR: hazard ratio; OS1: overall survival 1; OS2: overall survival 2; TTB: time to brain metastasis.

\section{Discussion}

This study analyzed the survival data in primary lung ASC patients with BM. The results revealed that median time to $\mathrm{BM}$ for all patients, including those occurred BM at the time of diagnosis was about 6 months. The OS data were shown according to two different starting events. TTB longer than 12 months and resection for $\mathrm{BM}$ lesions were independent predictors for a longer OS1, and treatment cycles more than 3 was an independent predictor for a longer OS2.

In clinical experience, patients with $\mathrm{BM}$ have a deterioration in performance status (PS) and a very limited survival time [10]. Thus, the appropriate management for NSCLC patients with BM is still an important issue in clinical practice. Lung ASC is an uncommon lung cancer type, accounting for $0.4-4 \%$ of all lung tumors. Due to its rarity, ASC patients with $\mathrm{BM}$ have received far less attention in clinical practice. We conducted this study as evidence in ASC patients with BM was very limited to date.

ASC has been reported to be an extremely aggressive subtype and patients with primary lung ASC had a poorer prognosis compared with those with a pure adenocarcinoma or squamous cell carcinoma subtype $[2,7,8]$. The aggressive biological behavior of lung ASC can be reflected in our findings: (1) The primary ASC patients with BM collected in this study were predominantly young and occurred tumor with low differentiations; (2) Most patients were diagnosed with an advanced clinical stage 
(stages IIIB-IV); and (3) The relative short time from diagnosis to occur BM and low survival time regardless of the calculation method of OS.

ASC patients are likely to occur BM as the TTB identified from our study was less than 6 months. In addition, 13 patients $(31 \%)$ was identified $\mathrm{BM}$ at the time of ASC diagnosis. The 1-year, 2-year and 3-year survival rates were relative low in ASC patients with $\mathrm{BM}$ according to the results, compared to that in unselected ASC patients. We did not calculate the 5 -year survival rate in this study as the estimated OS was very low in lung ASC patients with intracranial metastasis. Other studies have reported that the 5 -year survival rate for unselected lung ASC patients varied between $6.2 \%$ and $25.4 \%$ [2,3,7,8,11].

In the multivariate survival analysis, we identified that TTB longer than 12 months and resection for $\mathrm{BM}$ lesions were independent predictors for a longer survival when survival data was calculated from the time ASC was diagnosed, and that standard chemotherapy cycles more than 3 was an independent predictor for a longer survival when survival data was calculated from the time BM was identified. Thus, primary lung ASC patients are recommended to have their $\mathrm{BM}$ lesions resected if possible when they were identified BM. However, many patients do not have the chance to have their $\mathrm{BM}$ lesions removed as they occur multiple BM lesions. For these patients, standard chemotherapy for 4-6 cycles plus whole brain radiotherapy (WBRT) is needed. Other factors may also influence the survival of ASC. Some studies have reported that the percentages of adenocarcinoma and squamous cell carcinoma within the ASC could influence survival $[3,8,12,13]$. But the authors did not draw consistent conclusions. No statistical significant differences were found according to the percentage of adenocarcinomas component by some studies [3,12]. In contrast to these results, some authors observed that patients with a balanced component within the two ADS histologic types have better prognosis $[8,13]$. In addition, these studies were conducted in unselected ASC patients, and whether percentages of adenocarcinoma and squamous cell carcinoma could influence the survival of ASC patients with BM remains unknown.

The present study has some limitations. Firstly, this was a retrospective study and the sample size was relatively small due to the low incidence of primary lung ASC with BM. Secondly, the representability might be insufficient as it was a single center study. Therefore, the results of this study should be interpreted with caution as they need to be confirmed by subsequent multicenter studies with larger sample sizes.
In conclusion, the study analyzed the survival data in primary lung ASC patients with BM. This study shows that resection of BM if possible, and standard chemo-radiotherapy in patients with multiple BM lesions are associated with longer overall survival.

\section{Acknowledgments}

This study was supported by the National Nature Science Foundation of China (Grant No. 81472175) and Medical Guidance Project of Shanghai Science and Technology Committee (Grant No. 15411961500).

\section{Competing Interests}

The authors have declared that no competing interest exists.

\section{References}

1. Siegel R, Miller K, Jemal A. Cancer statistics, 2016. CA Cancer J Clin. 2016; 66(1):10-29.

2. Filosso PL, Ruffini E, Asioli S, et al. Adenosquamous lung carcinomas: a histologic subtype with poor prognosis. Lung Cancer. 2011; 74:25-9.

3. Shimizu J, Oda M, Hayashi Y, et al. A clinicopathologic study of resected cases of adenosquamous carcinoma of the lung. Chest. 1996; 109:989-94.

4. Fitzgibbons PL, Kern WH. Adenosquamous carcinoma of the lung: a clinical and pathologic study of seven cases. Hum Pathol. 1985; 16(5):463-6.

5. Ishida T, Kaneko S, Yokoyama H, et al. Adenosquamous carcinoma of the lung. Clinicopathologic and immunohistochemical features. Am J Clin Pathol. 1992; 97:678-85.

6. Travis WD, Brambilla E, Burke AP, et al. Introduction to The 2015 World Health Organization Classification of Tumors of the Lung, Pleura, Thymus, and Heart. J Thorac Oncol. 2015; 10:1240-1242.

7. Maeda H, Matsumura A, Kawabata T, et al. Adenosquamous carcinoma of the lung: surgical results as compared with squamous cell and adenocarcinoma cases. Eur J Cardiothorac Surg. 2012; 41:357-61.

8. Gawrychowski J, Bruliński K, Malinowski E, et al. Prognosis and survival after radical resection of primary adenosquamous lung carcinoma. Eur J Cardiothorac Surg. 2005; 27:686-92.

9. Taillibert S, Le Rhun É. Epidemiology of brain metastases. Cancer Radiother. 2015; 19:3-9.

10. Langer CJ, Mehta MP. Current management of brain metastases, with a focus on systemic options. J Clin Oncol. 2005; 23:6207-19.

11. Nakagawa K, Yasumitu T, Fukuhara K, et al. Poor prognosis after lung resection for patients with adenosquamous carcinoma of the lung. Ann Thorac Surg. 2003; 75:1740-4

12. Takamori S, Noguchi M, Morinaga S, et al. Clinicopathologic characteristics of adenosquamous carcinoma of the lung. Cancer. 1991; 67:649-54.

13. Zhao $\mathrm{H}$, Yang $\mathrm{H}$, Yao $\mathrm{F}$, et al. Improved survival associated with a balanced structure between adenomatous and squamous components in patients with adenosquamous carcinoma of the lung. Eur J Surg Oncol. 2016;42(11):1699-1706. 